\title{
Reimplantation of the aortic valve at 20 years
}

Tirone E. David, MD, Carolyn M. David, BN, Christopher M. Feindel, MD, and Cedric Manlhiot, PhD

\section{ABSTRACT}

Objective: To provide additional information on clinical and echocardiographic outcomes after reimplantation of the aortic valve (RAV) in patients with aortic root aneurysm.

Methods: All 333 patients who underwent RAV at our hospital between 1989 and 2012 were followed prospectively with periodical clinical assessment and echocardiography. The mean duration of clinical follow-up was $10.3 \pm 6.8$ years, and follow-up was completed within 2 years before this report.

Results: The study cohort had a mean patient age was $46 \pm 5$ years and was $78 \%$ male. The aortic root aneurysm was associated with Marfan syndrome in 124 patients, with bicuspid aortic valve in 45 , with type A aortic dissection in 28 , and with moderate to severe aortic regurgitation (AR) in 144. In addition to the RAV, 113 patients underwent another cardiac procedure owing to associated pathology. There were 4 early deaths ( $<90$ days) and 35 late deaths. Survival at 15 and 20 years was $77.9 \pm 2.9 \%$ and $72.4 \pm 3.8 \%$, respectively. Eleven patients developed moderate or severe AR during the follow-up; using interval censoring, $96.2 \pm 1.0 \%$ were free from this event at 15 to 20 years. Six patients underwent reoperation on the aortic valve at 2 days to 23 years after RAV, including 1 patient for endocarditis and 5 patients for AR; freedom from reoperation at 15 to 20 years was $96.9 \pm 1.3 \%$. Seventeen patients sustained stroke or transient ischemic attacks; $92.5 \pm 2.8 \%$ were free from thromboembolism at 15 and 20 years. Three patients developed infective endocarditis: 1 in the aortic valve and 2 in the mitral valve.

Conclusions: RAV continues to provide excellent clinical results and stable aortic valve function during the second decade of observation. (J Thorac Cardiovasc Surg 2017;153:232-8)

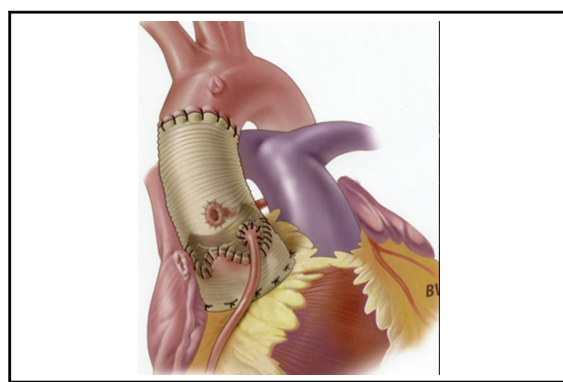

Reimplantation of the aortic valve.

\section{Central Message}

Reimplantation of the aortic valve to treat aortic root aneurysm in young adults continues to provide excellent survival and stable aortic valve during the second decade of follow-up.

\section{Perspective}

This study provides additional information on the clinical and echocardiographic outcomes of reimplantation of the aortic valve to treat aortic root aneurysms in a relatively large cohort of young adults followed prospectively for up to 25 years. Reimplantation of the aortic valve to treat aortic root aneurysm in young adults continues to provide excellent survival and stable aortic valve during the second decade of follow-up.

See Editorial Commentary page 239.

See Editorial page 230.
Reimplantation of the aortic valve (RAV) into a cylindrical Dacron graft is an alternative operation to composite replacement of the aortic valve and ascending aorta (Bentall operation) in patients with an aortic root aneurysm with or without associated genetic syndromes and with normal or

From the Division of Cardiac Surgery of the Peter Munk Cardiac Centre at Toronto General Hospital and the University of Toronto, Toronto, Ontario, Canada.

This project was funded by the Academic Enrichment Fund of the Division of Cardiovascular Surgery of Toronto General Hospital.

Received for publication May 15, 2016; revisions received Sept 28, 2016; accepted for publication Oct 13, 2016; available ahead of print Dec 4, 2016

Address for reprints: Tirone E. David, MD, 200 Elizabeth St. 4N453, Toronto, ON M5G 2C4, Canada (E-mail: tirone.david@uhn.ca).

$0022-5223 / \$ 36.00$

Copyright $($ c 2016 by The American Association for Thoracic Surgery

http://dx.doi.org/10.1016/j.jtcvs.2016.10.081 near-normal aortic cusps. ${ }^{1}$ Whether RAV offers a survival advantage over the Bentall procedure in the treatment of aortic root aneurysms remains controversial. RAV certainly is associated with lower rates of hemorrhage and thromboembolism ${ }^{2,3}$; however, it also may be associated with an unacceptably high rate of aortic regurgitation (AR), which eventually leads to the need for reoperation. ${ }^{4,5}$

Scanning this QR code will take you to the article title page. 

Abbreviations and Acronyms
$\mathrm{AR}=$ aortic regurgitation
$\mathrm{HR}=$ hazard ratio
$\mathrm{CI}=$ confidence interval
$\mathrm{RAV}=$ reimplantation of the aortic valve

RAV is a complex operation, altering the geometry of the aortoventricular junction, the crescent shape of each cusp attachment to the aortoventricular junction, the heights of the commissures, and the diameter of the sinotubular junction. In addition, numerous technical modifications have been introduced over the years, some of questionable value. The original RAV was done with a cylindrical Dacron graft, and this has provided the best clinical outcomes and the most stable aortic valve function. ${ }^{6}$

The present study is an update of the clinical outcomes of RAV performed mostly in young adults with aortic root aneurysm who have been followed prospectively with periodical images of the aortic valve and aorta since we introduced this operation in $1989 .{ }^{6}$

\section{PATIENTS AND METHODS}

Between August 3, 1989, and December 31, 2012, 333 consecutive patients with aortic root aneurysm underwent RAV at Toronto General Hospital (Tables 1 and 2). The aortic valve was reimplanted into a straight tubular Dacron graft in 216 patients and into a graft surgically tailored to create neo-aortic sinuses in 117 patients. Intraoperative transesophageal echocardiography was used, and all patients underwent transthoracic echocardiography before hospital discharge. Echocardiographic studies were requested every year during the first decade after surgery and less frequently thereafter. Approximately one-half of these studies were performed in our hospital, and the remainder were performed in external laboratories by registered cardiac sonographers under supervision of a cardiologist. Quantification of AR was based on comprehensive interpretation of all specific, supportive, and quantitative measurements as recommended by the American Society of Echocardiography. ${ }^{7,8}$

Patients who underwent concomitant mitral valve repair or developed atrial fibrillation postoperatively received anticoagulant therapy with warfarin sodium during the first 3 months after surgery. All other patients were prescribed aspirin $(81 \mathrm{mg} /$ day). Patients with syndromic aortic root aneurysm or aortic dissection were given a beta-blocker postoperatively.

The follow-up was closed on December 31, 2015, for this report. At that time, we had clinical information for all patients and recent $(<2$ years $)$ echocardiographic data for all but 6 international patients, for whom no study had been done during the most recent 5 -year period. The mean follow-up was $10.3 \pm 6.8$ years (range, $3-25$ years). This study was approved by the Review Ethics Board of University Health Network.

\section{Statistical Analysis}

Data are reported as mean with standard deviation, median with interquartile range (25th-75th percentile), or frequency as appropriate. Freedom from mortality was calculated using Kaplan-Meier survival estimates. Freedom from time-dependent outcomes other than mortality and moderate and severe AR was calculated using the cumulative incidence function, accounting for the competing risks of mortality and the outcome of interest. Univariable risk factor analysis was performed on the cumulative incidence function using Cox regression, and hazard ratios
(HRs) with $95 \%$ confidence intervals (CIs) and $P$ values are reported. Preoperative variables with a univariable $P$ value $<.25$ were tested in a multivariable model using Cox regression and HRs to determine the independent predictors of postoperative adverse events. Given that the presence of $\mathrm{AR}$ can be captured only intermittently at the time of echocardiography, the time of AR cannot be measured precisely. As a result, we treated time to develop moderate and severe AR as an interval-censored outcome. We used the competing-risk method with interval censoring as suggested by Leffrondre et al, ${ }^{9}$ and conducted analyses (modeling and risk factor analysis with the Fine-Gray method) using $\mathrm{R}$ with the MHCD package. ${ }^{10}$ In addition, we used serial echocardiography data to create a longitudinal ordinal logistic regression model to determine the progression of AR over time. Time since initial operation was modeled as a third-order polynomial function, and an autoregressive covariance structure was used to adjust for the correlation between the multiple echocardiograms available for each patient (both options selected based on the quasi-Akaike information criterion). Estimates of the proportion of patients in each of the different aortic valve functional states over time were adjusted to take into consideration the proportion of patients who had died or had undergone reoperation. Unless noted otherwise, analyses were performed using SAS 9.4 (SAS Institute, Cary, NC).

\section{RESULTS \\ Early Mortality and Morbidity}

Four deaths occurred during the first 90 days after surgery. The causes of death were low cardiac output syndrome due to perioperative myocardial infarction in 1 patient, acute type $\mathrm{B}$ aortic dissection with malperfusion of the splanchnic vessels on the day after surgery in 1 patient with Marfan syndrome, Clostridium difficile colitis in 1 patient while in a convalescence hospital at 3 weeks after surgery, and stroke likely due to atrial fibrillation in 1 patient at home 6 weeks after surgery.

Reexploration of the mediastinum for bleeding or tamponade was performed in 29 patients $(8.7 \%)$. Four patients underwent early cardiac reoperation on cardiopulmonary bypass: 1 with Bentall procedure for moderate AR, likely owing to an incorrectly performed operation (our case 2); 1 for reexploration of the aortic root and coronary artery buttons because of refractory ventricular fibrillation; 1 with mitral valve repair for perforation of the anterior leaflet of the mitral valve by the aortic annuloplasty suture, and 1 with mitral valve re-repair owing to systolic anterior motion of the anterior leaflet. In the patients who underwent reexploration of the aortic root and coronary artery buttons, a large amount of white clots in all 3 aortic sinuses was found, which histological examination revealed to be mostly platelets; the circulating blood was totally depleted from platelets, and heparininduced thrombocytopenia tests were negative. Laparotomy for repair of a ruptured liver was done in 1 patient. All 5 patients survived. Four patients experienced perioperative myocardial infarction, 1 of whom died. Five patients underwent implantation of a permanent transvenous pacemaker; among these patients, 2 developed renal failure requiring temporary dialysis, 3 had a superficial wound 
TABLE 1. Clinical characteristics

\begin{tabular}{|c|c|}
\hline Characteristic & Value \\
\hline Age, $y$, mean \pm SD & $46 \pm 5$ \\
\hline$<40 \mathrm{y}, \mathrm{n}(\%)$ & $117(35.3)$ \\
\hline $40-60 y, n(\%)$ & $150(45.1)$ \\
\hline$>60 y, n(\%)$ & $66(19.8)$ \\
\hline Male sex, n (\%) & $259(77.8)$ \\
\hline \multicolumn{2}{|l|}{ Electrocardiography findings, $\mathrm{n}(\%)$} \\
\hline Sinus rhythm & $325(97.5)$ \\
\hline Atrial fibrillation & $7(2.1)$ \\
\hline Heart block/pacemaker & $1(0.3)$ \\
\hline \multicolumn{2}{|l|}{ Previous cardiac surgery, n (\%) } \\
\hline Ross procedure & $2(0.6)$ \\
\hline Mitral valve repair & $3(0.9)$ \\
\hline Other & $9(2.7)$ \\
\hline Marfan syndrome, n (\%) & $128(38.4)$ \\
\hline Loeys-Dietz syndrome, n (\%) & $5(1.5)$ \\
\hline \multicolumn{2}{|l|}{ Associated disorders, $\mathrm{n}(\%)$} \\
\hline Diabetes mellitus & $11(3.3)$ \\
\hline Hypertension & $126(37.8)$ \\
\hline Hyperlipidemia & $69(20.7)$ \\
\hline $\mathrm{COPD}\left(\mathrm{FEV}_{1}<1\right)$ & $8(2.4)$ \\
\hline Previous stroke & $8(2.4)$ \\
\hline Peripheral vascular disease & $5(1.5)$ \\
\hline Renal failure (dialysis) & $4(1.2)$ \\
\hline Coronary artery disease, $\mathrm{n}(\%)$ & $29(8.7)$ \\
\hline Type A aortic dissection, n (\%) & $28(8.4)$ \\
\hline \multicolumn{2}{|l|}{ NYHA functional class, n (\%) } \\
\hline Class I & $203(61.1)$ \\
\hline Class II & $84(25.2)$ \\
\hline Class III & $20(6)$ \\
\hline Class IV & $25(7.5)$ \\
\hline \multicolumn{2}{|l|}{ Left ventricular ejection fraction, $\%, \mathrm{n}(\%)$} \\
\hline$\geq 60$ & $247(74.4)$ \\
\hline $40-59$ & $64(19.3)$ \\
\hline $20-39$ & $21(6.5)$ \\
\hline \multicolumn{2}{|l|}{ Aortic insufficiency, n (\%) } \\
\hline None or trivial & $89(26.7)$ \\
\hline Mild & $71(21.3)$ \\
\hline Moderate & $78(23.4)$ \\
\hline Severe & $66(19.8)$ \\
\hline Not recorded & $29(8.7)$ \\
\hline Mitral regurgitation (moderate/severe), n (\%) & $26(7.8)$ \\
\hline Tricuspid regurgitation (moderate/severe), n (\%) & $1(0.3)$ \\
\hline \multicolumn{2}{|l|}{ Aortic valve morphology, n (\%) } \\
\hline Tricuspid aortic valve & $284(85.8)$ \\
\hline Bicuspid aortic valve & $45(13.5)$ \\
\hline Pulmonary autograft & $2(0.6)$ \\
\hline Aortic root diameter, $\mathrm{mm}$, mean $\pm \mathrm{SD}$ & $55 \pm 4$ \\
\hline$<50 \mathrm{~mm}, \mathrm{n}(\%)$ & $39(11.9)$ \\
\hline $50-55 \mathrm{~mm}, \mathrm{n}(\%)$ & $171(51.3)$ \\
\hline $56-60 \mathrm{~mm}, \mathrm{n}(\%)$ & 72 (21.6) \\
\hline$>60 \mathrm{~mm}, \mathrm{n}(\%)$ & $22(6.6)$ \\
\hline Not recorded, n (\%) & $29(8.7)$ \\
\hline \multicolumn{2}{|l|}{ Indications for surgery ( 1 or more), $\mathrm{n}(\%)$} \\
\hline Chest pain & $20(6.0)$ \\
\hline Heart failure & $22(6.6)$ \\
\hline
\end{tabular}

TABLE 1. Continued

\begin{tabular}{lc}
\hline \multicolumn{1}{c}{ Characteristic } & Value \\
\hline Cardiogenic shock & $2(0.6)$ \\
Syncope & $8(2.4)$ \\
Aortic root diameter & $264(79.2)$ \\
Degree of aortic insufficiency & $66(19.8)$ \\
Type A aortic dissection & $28(8.4)$ \\
Operations performed & \\
Aortic valve reimplantation & $333(100)$ \\
Graft size, mm, mean $\pm \mathrm{SD}$ & $30.3 \pm 2.4$ \\
Aortic cusp plication, $\mathrm{n}(\%)$ & $139(39.3)$ \\
Free margin reinforcement with Gore-Tex, $\mathrm{n}(\%)$ & $74(22.2)$ \\
Neo-aortic sinus creation, $\mathrm{n}(\%)$ & $117(35.1)$ \\
Mitral valve repair, $\mathrm{n}(\%)$ & $26(7.8)$ \\
Tricuspid annuloplasty, $\mathrm{n}(\%)$ & $1(0.3)$ \\
Coronary artery bypass, $\mathrm{n}(\%)$ & $29(8.7)$ \\
Patch angioplasty of left main coronary, $\mathrm{n}(\%)$ & $5(1.5)$ \\
Replacement of aortic arch/hemiarch, $\mathrm{n}(\%)$ & $59(17.7)$ \\
Closure of atrial septal defect, $\mathrm{n}(\%)$ & $19(5.7)$ \\
Closure of ventricular septal defect, $\mathrm{n}(\%)$ & $2(0.6)$ \\
Maze procedure, $\mathrm{n}(\%)$ & $5(1.5)$ \\
Repair of abdominal aortic aneurysm, $\mathrm{n}(\%)$ & $1(0.3)$ \\
Cardiopulmonary bypass time, min, mean $\pm \mathrm{SD}$ & $142 \pm 33$ \\
Aortic clamping time, min, mean $\pm \mathrm{SD}$ & $118 \pm 28$ \\
\hline
\end{tabular}

$S D$, Standard deviation; $C O P D$, chronic obstructive pulmonary disorder; $F E V_{l}$, forced expiratory volume in 1 second; NYHA, New York Heart Association.

infection, and 1 patient had a deep sternal infection. Thirtyone patients required assisted ventilation for more than 24 hours. New transient atrial fibrillation developed in 67 patients $(20.1 \%)$, and transfusion of any blood product was necessary in 167 patients $(50 \%)$.

\section{Late Mortality and Morbidity}

There were 35 late deaths: 4 sudden, 6 due to complications of aortic dissection, 2 due to myocardial infarction, 2 due to heart and renal failure, and 21

TABLE 2. Perioperative outcome

\begin{tabular}{lc}
\hline \multicolumn{1}{c}{ Outcome } & Value \\
\hline Ventilation time, h, median (IQR) & $5(4-9)$ \\
ICU stay, h, median (IQR) & $24(21-47)$ \\
Hospital stay, d, median (IQR) & $6(5-8)$ \\
Reoperations before discharge, $\mathrm{n}(\%)$ & $32(9.6)$ \\
Bleeding/tamponade & $29(8.7)$ \\
Cardiac arrest & $1(0.3)$ \\
Bentall & $1(0.3)$ \\
Repair of ruptured liver & $1(0.3)$ \\
Myocardial infarction, n (\%) & $4(1.2)$ \\
Insertion of permanent pacemaker, n (\%) & $5(1.5)$ \\
Postoperative new atrial fibrillation, n (\%) & $75(22.5)$ \\
Transient ischemic attack, n (\%) & $2(0.6)$ \\
Transfusion of blood products, $\mathrm{n}(\%)$ & $167(50.1)$ \\
Mortality, $\mathrm{n}(\%)$ & $4(1.2)$ \\
\hline IQR, Interquartile range; $I C U$, intensive care unit.
\end{tabular}




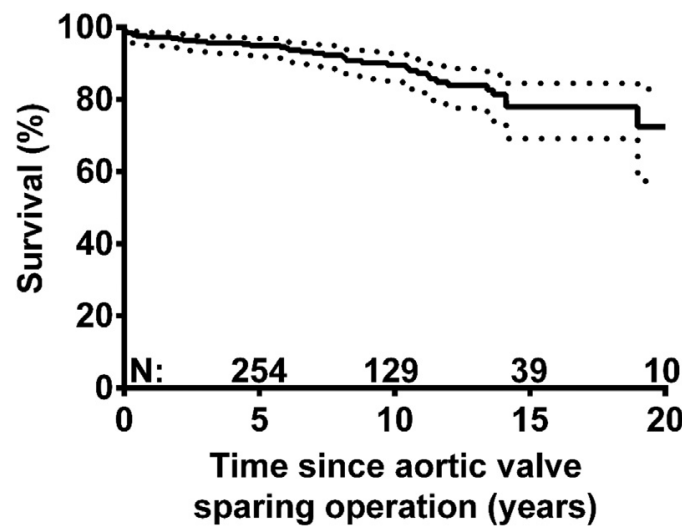

FIGURE 1. Long-term survival.

non-cardiovascular-related. Survival at 10,15 , and 20 years was $89.5 \pm 2.0 \%, 77.9 \pm 3.9 \%$, and $72.4 \pm 6.5 \%$, respectively (Figure 1). Multivariable analysis identified age by 5 year increments (hazard ratio [HR], 1.27; 95\% CI, 1.11$1.46 ; P=.001)$, coronary artery disease (HR, $1.60 ; 95 \%$ CI, 1.05-2.44; $P=.03$ ) and elevated creatinine (per 50 $\mu \mathrm{ml} / \mathrm{L}$ above normal) (HR, $1.23 ; 95 \%$ CI, 1.12-1.35; $P<.001)$ as factors associated with increased mortality.

Eight patients sustained a stroke, 2 of whom died. Four of these 8 patients were on warfarin, therapy, 2 were on aspirin therapy, and 2 were on no antithrombotic therapy. Nine patients experienced transient ischemic attack, 6 of whom were receiving aspirin therapy. The freedom from stroke and transient ischemic attacks at 10,15 , and 20 years was $95.0 \pm 1.4 \%, 92.5 \pm 2.8 \%$, and $92.5 \pm 2.8 \%$, respectively. Age (by 5-year increments) was the sole factor associated with stroke or transient ischemic attack (HR, 1.308; 95\% CI, 1.081-1.583; $P=.006$ ).

One patient developed infective endocarditis of the aortic valve with aortic root abscess due to Staphylococcus aureus at 23 years after RAV and underwent aortic root replacement with an aortic homograft. Two patients developed infective endocarditis of the mitral valve; 1 of these patients required mitral valve repair, and the other was treated successfully with antibiotics alone. These 3 patients survived.

Eight patients developed moderate AR and 3 developed severe AR postoperatively. Using interval censoring, freedom from moderate and severe AR was $98.0 \pm 0.5 \%$ at 5 years and $96.2 \pm 1.0 \%$ at 10,15 and 20 years. Using time of echocardiography as the time of event, these percentages were $95.4 \pm 1.7 \%$ at 10 years, $92.3 \pm 2.8 \%$ at 15 years, and $92.3 \pm 2.8 \%$ at 20 years. Progression of AR over time using serial echocardiography data is depicted in Figure 2, and the relevant data are presented in Table 3. Creation of neo-aortic sinuses (HR, 1.87; 95\% CI, 1.02-3.42; $P=.04$ ) and reinforcement of the free margin of the cusps with Gore-Tex sutures (HR, 3.25;

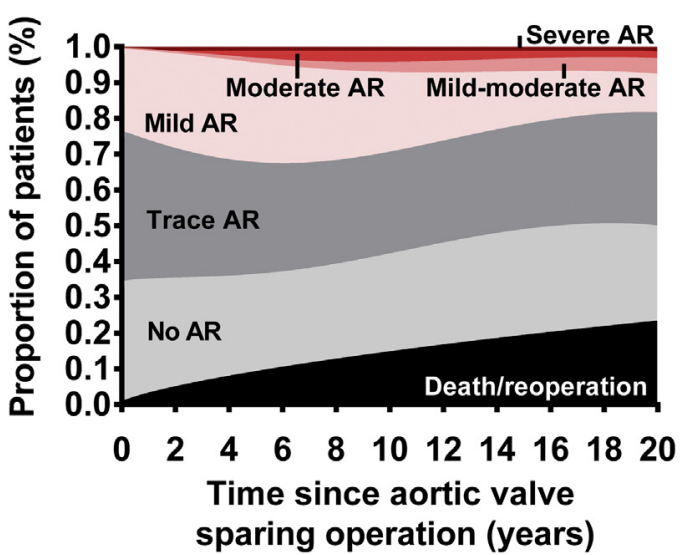

FIGURE 2. Aortic regurgitation after aortic valve reimplantation over time. $A R$, Aortic regurgitation.

95\% CI, 1.42-7.41; $P=.005)$ were associated with the development of moderate or severe AR on univariable analysis, but not on multivariable analysis. Cusp plication was not statistically associated with the development of moderate or severe AR (HR, 1.43; 95\% CI, 10-81-2.53; $P=.22$ ).

Six patients underwent reoperation on the aortic valve between 2 days and 23 years after the initial surgery, including 1 for endocarditis and 5 for AR. One patient developed a perforation of the right coronary cusp without obvious explanation, which was repaired by H. J. Schäfers at 6 months after RAV (personal communication). One patient needed coronary artery bypass, and because of his $\mathrm{AR}$, the aortic valve was replaced at the same time in Athens, Greece, at 9 years after RAV. Three patients underwent aortic valve replacement because of moderate or severe AR in our hospital, 1 each at 2 days, 8 years, and 9 years after RAV. The first of these replacements was required because of a technical error, and the latter 2 were necessary because of degenerative changes in the cusps of the aortic valve (1 bicuspid and 1 tricuspid). All patients survived reoperation. Freedom from aortic valve reoperation at 10,15 , and 20 years was $96.9 \pm 1.3 \%$. In addition to the aortic valve reoperations, 1 patient underwent total arch replacement with an elephant trunk for chronic type A aortic dissection, 3 patients underwent mitral valve repair, and 1 patient underwent replacement of the thoracoabdominal aorta for chronic dissecting aneurysm.

Before RAV, 28 patients had acute type A aortic dissection, and 3 had chronic type B aortic dissection (14 with Marfan syndrome, 1 with Loeys-Dietz syndrome, and 16 with nonsyndromic aortic root aneurysm). Five of these 31 patients died due rupture of the false lumen. After RAV, 11 patients developed new type B aortic dissection, and 1 patient developed dissection of the aortic arch, with 2 deaths due to malperfusion. Nine of the patients who 
TABLE 3. Progression of AR over time

\begin{tabular}{|c|c|c|c|c|c|}
\hline Parameter & $1 \mathrm{y}, \%(95 \% \mathbf{C I})$ & $5 \mathrm{y}, \%(95 \%$ CI $)$ & $10 \mathrm{y}, \%(95 \% \mathrm{CI})$ & $15 \mathrm{y}, \%(95 \% \mathrm{CI})$ & $20 \mathrm{y}, \%(95 \% \mathrm{CI})$ \\
\hline No. of patients & 302 & 254 & 129 & 39 & 10 \\
\hline Mortality or reoperation, $\%$ & 2.6 & 8.7 & 14.2 & 18.8 & 22.8 \\
\hline \multicolumn{6}{|l|}{ Degree of AR, median (IQR) } \\
\hline Severe & $0.2(0.1-2.1)$ & $0.6(0.3-1.4)$ & $0.8(0.3-2.7)$ & $0.7(0.2-2.4)$ & $1.3(0.3-5.1)$ \\
\hline Moderate & $1.3(0.7-2.4)$ & $3.2(1.9-5.5)$ & $4.3(2.5-7.1)$ & $3.4(1.3-8.2)$ & $2.6(0.8-8.0)$ \\
\hline Mild-moderate & $0.5(0.2-1.7)$ & $1.4(0.7-2.7)$ & $2.8(1.7-4.8)$ & $3.7(1.7-7.6)$ & $4.4(1.4-13.0)$ \\
\hline Mild & $25.0(21.1-29.3)$ & $27.9(23.5-32.6)$ & $22.3(18.0-27.2)$ & $14.9(10.0-21.5)$ & $10.9(4.5-23.5)$ \\
\hline Trivial & $38.8(34.6-43.1)$ & $31.3(26.9-36.0)$ & $28.5(24.1-33.2)$ & $29.3(22.1-37.4)$ & $31.5(19.5-45.1)$ \\
\hline None & $31.0(26.9-35.4)$ & $27.1(22.7-31.8)$ & $27.6(22.8-32.8)$ & $28.4(21.8-35.8)$ & $24.9(15.1-37.3)$ \\
\hline
\end{tabular}

$A R$, Aortic regurgitation; $C I$, confidence interval; $I Q R$, interquartile range.

developed new aortic dissection had Marfan syndrome. All patients with Marfan syndrome were on beta-blocker therapy when the new dissection occurred. At the last followup contact, 283 patients were alive and free from reoperation on the aortic valve: $255(90 \%)$ were in New York Heart Association functional class I, 24 (8.5\%) were in class II, and $4(1.4 \%)$ were in class III.

\section{DISCUSSION}

Aortic root aneurysm in young patients usually starts with dilatation of the aortic sinuses. Over time, the dilatation extends proximally into the aortoventricular junction and distally into the sinotubular junction. These aneurysms are often associated with genetic syndromes. Aortic root aneurysms in older patients is often a consequence of a degenerative process that starts with dilatation of the ascending aorta and proceeds with the dilatation extending proximally into the sinotubular junction and aortic sinuses, but seldom affecting the aortoventricular junction. Clinical experience has shown that remodeling of the aortic root is associated with a high failure rate when performed in the former type of aortic root aneurysm, but not in the latter type..$^{1,11-14}$

The principal cause of failure of the remodeling procedure in patients with aortic root aneurysm associated with a genetic syndrome is dilatation of the aortoventricular junction many years after surgery ${ }^{13,14}$; therefore, RAV is likely the best option for preserving the aortic valve in young patients with aortic root aneurysm. Remodeling of the aortic root is a useful operation and a simpler procedure than RAV, however, and is probably the best option for preserving the aortic valve in older patients with ascending aortic aneurysm and AR secondary to dilatation of the sinotubular junction. ${ }^{12,15}$

A recent study from Johns Hopkins Hospital ${ }^{2}$ compared the late outcomes of aortic valve-sparing operations (69 patients with RAV and 29 with remodeling) with Bentall (67 patients) and found equivalent results in terms of survival, risk of reoperation, and endocarditis, but "significantly fewer thromboembolic and hemorrhagic events."
Hopkins' surgeons favor RAV in patients with normal aortic cusps. $^{2}$ We compared outcomes in 253 patients who underwent aortic valve-sparing operations, 180 patients who received a replacement tissue valve, and 183 patients who received a replacement mechanical valve. ${ }^{3}$ After adjusting for clinical covariates, the aortic valve-sparing operation was associated with reduced cardiac mortality and valve-related complications compared with aortic root replacement with a mechanical or tissue valve. ${ }^{3}$

Ideal patients for RAV have a relatively small aortic root $(<55 \mathrm{~mm})$, no AR, and grossly normal cusps on surgical inspection. These patients should have no more trace AR after RAV in the operating room; if they do, it is usually due to technical error. Malaligned aortoventricular junction inside the graft, altered contour of the crescent-shaped aortic annulus, cusp prolapse, and incorrect graft size are the most frequent causes of early AR. In our experience with 333 consecutive patients who underwent RAV, only 11 patients developed moderate or severe AR during a mean follow-up of 10 years. Cusp reinforcement with Gore-Tex sutures and the creation of neo-aortic sinuses were associated with an increased risk of moderate or severe AR on univariable analysis but not on multivariable analysis. The challenge here was that we had only 11 events, which means that numerous factors were close to significant and would likely be significant with more events. In addition, 18 patients exhibited mild to moderate AR on some echocardiograms but not others, hindering interpretation of the degree of AR. Thus, further follow-up is needed to determine the factors associated with progression of AR.

A recent multicenter study showed that any AR occurring soon after RAV increased the risk of progressive AR and eventually the likelihood of reoperation. ${ }^{4}$ As illustrated in Figure 2, almost one-fourth of our patients left the hospital with mild AR, but only 3 progressed to moderate AR, and we could not establish a relationship between the degree of AR on hospital discharge and the development of moderate or severe AR during follow-up. We believe that more important than the absence of trivial or mild AR at the completion of RAV is the geometry of the aortic cusps, 
coaptation height, and coaptation length, as described by Kunihara et al. ${ }^{16}$

The use of commercially available Dacron grafts with aortic sinuses, such as the Gelweave Valsalva (Vascutek, Renfrewshire, UK) or the Cardioroot (Atrium Medical, Hudson, NH), further complicates the performance of this operation, because their sinuses are spherical and will deform the aortoventricular junction if correctly implanted inside the graft. Another problem with these grafts is that the height of the sinuses may not coincide with height of the native aortic valve commissures, creating another technical and anatomic difficulty. De Paulis et $\mathrm{al}^{5}$ recently published the results of RAV with the Gelweave Valsalva, which appear to be suboptimal, with approximately $10 \%$ reoperations and $13 \%$ moderate or severe AR at 10 years.

If one believes that aortic sinuses are important for the durability of this operation (something that we have not been able to prove to be beneficial), then an anatomically correct Dacron graft with neo-sinuses (Uni-Graft W SINUS; Braun, Melsungen, Germany) is now available. ${ }^{17,18}$ A study using 4-dimensional magnetic resonance imaging in patients who underwent RAV with this graft showed fairly normal flows with near-physiological sinus vortex formation and transvalvular pressure gradients. ${ }^{19}$ Experience with this graft is limited to date,$^{17,18}$ and further studies are needed to verify that it maintains its geometry after implantation, given that tubular Dacron grafts tend to increase in diameter with time, particularly in the ascending aorta, ${ }^{20}$ and the sinuses may become spherical. This anatomically correct Dacron graft with sinuses mimics the normal aortic root and may prove to be the ideal graft for RAV; however, until that time, even with the unphysiological properties of RAV with a cylindrical Dacron graft, this remains the best and most durable operation, as documented in this report. Over the last 2 years, we have returned to the original RAV, that is, reimplantation into a cylindrical graft without creating neo-aortic sinuses. In our experience, the creation of neo-aortic sinuses appears to adversely affect the durability of RAV; however, as mentioned above, further follow-up is needed.

Another group of patients with abnormal aortic cusps that may benefit from RAV is the those with a bicuspid aortic valve with AR. ${ }^{21}$ Patients with a bicuspid aortic valve are likely to come to surgical attention for the AR rather than for the size of the aortic aneurysm. If the aortic cusps are well developed (thin, pliable, and of adequate height), the AR is often caused by prolapse of the conjoint cusp and dilatation of the aortic annulus. Simple correction of the cusp prolapse and subcommissural plication to reduce the diameter of the aortic annulus has not provided lasting results. $^{22}$ A surgical group from Brussels has reported better clinical outcomes when these valves are treated with $\mathrm{RAV}^{21}$ We agree with their approach when the aortic sinuses are $>40 \mathrm{~mm}$, but consider it an aggressive procedure if the aortic sinuses are normal. In these patients, we prefer to combine cusp repair with an external annuloplasty band to correct the dilated aortic annulus, similar to what we have described for the remodeling procedure. ${ }^{23}$

RAV also has been performed in patients with acute type A aortic dissection. Surgery for acute aortic dissection remains challenging and humbling even for experienced surgeons, and continues to be associated with high operative mortality and morbidity. Adding RAV at the time of surgery for acute dissection, which is primarily intended to save the patient's life, might not be the best approach, except perhaps in the hands of experienced aortic surgeons.

Dilatation of the pulmonary autograft is the principal mode of failure of the Ross procedure, and if the autograft cusps are normal, then an aortic valve-sparing operation can be performed. ${ }^{24} \mathrm{~A}$ recent multicenter study from Europe including 86 patients with a failed Ross procedure who had an aortic valve-sparing operation showed a freedom from reoperation of only $76 \%$ at 8 years. ${ }^{24} \mathrm{We}$ consider this an suboptimal result, and believe that only patients with normal pulmonary autograft cusps should be subjected to an aortic valve-sparing operation.

This present study has several limitations, most importantly the lack of accurate criteria for patient selection for RAV and the fact that all operations were performed by only 2 experienced aortic surgeons. For these reasons, the results presented might not be generalizable. Of possible importance is the fact that we have been relatively conservative when it comes to RAV. We did not use any patch augmentation of cusps in this series, and most patients had normal or near-normal cusps at the time of surgery.

\section{CONCLUSIONS}

RAV has been performed for more than 2 decades, and the long-term results have been excellent in our experience. The risk of AR after surgery is low, probably lower than with any other type of valve repair. This operation has made a major difference in the lives of young adults with aortic root aneurysms.

\section{Conflict of Interest Statement}

Authors have nothing to disclose with regard to commercial support.

\section{References}

1. David TE, David CM, Manlhiot C, Colman J, Crean AM, Bradley T. Outcomes of aortic valve-sparing operations in Marfan syndrome. J Am Coll Cardiol. 2015; 66:1445-53.

2. Price J, Magruder JT, Young A, Grimm JC, Patel ND, Alejo D, et al. Long-term out comes of aortic root operations for Marfan syndrome: a comparison of Bental versus aortic valve-sparing procedures. J Thorac Cardiovasc Surg. 2016;151:330-6.

3. Ouzounian M, Rao V, Manlhiot C, Abraham N, David C, Feindel CM, et al. Valve-sparing root replacement compared with composite valve graft procedures in patients with aortic root dilatation. J Am Coll Cardiol. 2016;68:1838-47. 
4. Kari FA, Doll KN, Hemmer W, Liebrich M, Sievers HH, Richart D, et al. Residual and progressive aortic regurgitation after valve-sparing root replacement: a propensity-matched multi-institutional analysis in 764 patients. Ann Thorac Surg. 2016;101:1500-6.

5. De Paulis R, Chirichilli I, Scaffa R, Weltert L, Maselli D, Salica A, et al. Long-term results of the valve reimplantation technique using a graft with sinuses. J Thorac Cardiovasc Surg. 2016;151:112-9.

6. David TE, Feindel CM, David CM, Manlhiot C. A quarter of a century of experience with aortic valve-sparing operations. J Thorac Cardiovasc Surg. 2014;148:872-9; discussion 879-80.

7. Quiñones MA, Otto CM, Stoddard M, Waggoner A, Zoghbi WA Recommendations for quantification of Doppler echocardiography: a report from the Doppler Quantification Task Force of the Nomenclature and Standards Committee of the American Society of Echocardiography. J Am Soc Echocardiogr. 2002;15:167-84.

8. Zoghbi WA, Enriquez-Sarano M, Foster E, Grayburn PA, Kraft CD, Levine RA, et al. Recommendations for evaluation of the severity of native valvular regurgitation with two-dimensional and Doppler echocardiography. J Am Soc Echocardiogr. 2003; 16:777-802.

9. Leffondré K, Touraine C, Helmer C, Joly P. Interval-censored time-to-event and competing risk with death: is the illness-death model more accurate than the Cox model? Int J Epidemiol. 2013;42:1177-86.

10. Delord M, Génin E. Multiple imputation for competing risks regression with interval-censored data. J Stat Comput Simul. 2016;86:2217-28.

11. Yacoub MH, Gehle P, Chandrasekaran V, Birks EJ, Child A, Radley-Smith R. Late results of a valve-preserving operation in patients with aneurysms of the ascending aorta and root. J Thorac Cardiovasc Surg. 1998;115:1080-90.

12. Aicher D, Langer F, Lausberg H, Bierbach B, Schäfers HJ. Aortic root remodeling: ten-year experience with 274 patients. J Thorac Cardiovasc Surg. 2007;134:909-15.

13. David TE. Aortic valve sparing in different aortic valve and aortic root conditions. J Am Coll Cardiol. 2016;68:654-64.

14. de Oliveira NC, David TE, Ivanov J, Armstrong S, Eriksson MJ, Rakowski H, et al. Results of surgery for aortic root aneurysm in patients with Marfan syndrome. J Thorac Cardiovasc Surg. 2003;125:789-96.

15. Urbanski PP, Zhan X, Hijazi H, Zacher M, Diegeler A. Valve-sparing aortic root repair without down-sizing of the annulus. J Thorac Cardiovasc Surg. 2012;143: 294-302.
16. Kunihara T, Aicher D, Rodionycheva S, Groesdonk HV, Langer F, Sata F, et al Preoperative aortic root geometry and postoperative cusp configuration primarily determine long-term outcome after valve-preserving aortic root repair. J Thorac Cardiovasc Surg. 2012;143:1389-95.

17. Richardt D, Karluss A, Schmidtke C, Sievers HH, Scharfschwerdt M. A new sinus prosthesis for aortic valve-sparing surgery maintaining the shape of the root at systemic pressure. Ann Thorac Surg. 2010;89:943-6.

18. Schmidtke C, Sievers HH, Frydrychowicz A, Petersen M, Scharfschwerdt M, Karluss A, et al. First clinical results with the new sinus prosthesis used for valve-sparing aortic root replacement. Eur J Cardiothorac Surg. 2013;43: $585-90$.

19. Oechtering TH, Hons CF, Sieren M, Hunold P, Hennemuth A, Huellebrand M, et al. Time-resolved 3-dimensional magnetic resonance phase contrast imaging (4D Flow MRI) analysis of hemodynamics in valve-sparing aortic root repair with an anatomically shaped sinus prosthesis. J Thorac Cardiovasc Surg. 2016;152:418-27.e1.

20. Etz CD, Homann T, Silovitz D, Bodian CA, Luehr M, Di Luozzo G, et al. Vascular graft replacement of the ascending and descending aorta: do Dacron grafts grow? Ann Thorac Surg. 2007;84:1206-12; discussion 1212-3.

21. de Kerchove L, Boodhwani M, Glineur D, Vandyck M, Vanoverschelde JL, Noirhomme P, et al. Valve-sparing root replacement with the reimplantation technique to increase the durability of bicuspid aortic valve repair. $J$ Thorac Cardiovasc Surg. 2011;142:1430-8.

22. Casselman FP, Gillinov A, Akhrass R, Kasirajan V, Blackstone EH, Cosgrove DM. Intermediate-term durability of bicuspid aortic valve repair for prolapsing leaflet. Eur J Cardiothorac Surg. 1999;15:302-8.

23. David TE. Remodeling of the aortic root and preservation of the native aortic valve. Op Tech Cardiac Thorac Surg. 1996;1:44-56.

24. Mookhoek A, de Kerchove L, El Khoury G, Weimar T, Luciani GB, Mazzucco A, et al. European multicenter experience with valve-sparing reoperations after the Ross procedure. J Thorac Cardiovasc Surg. 2015; 150:1132-7.

Key Words: aortic insufficiency, aortic root aneurysm, aortic valve-sparing operation, David operation

Readers who found these articles interesting may also like to read the following papers found in recent and future issues of our sister publications, Seminars in Thoracic and Cardiovascular Surgery and Operative Techniques in Thoracic and Cardiovascular Surgery!

\section{Acquired: Aortic Disease}

Original Submission: Outcomes of Open Surgical Repair for Type B Dissecting Aortic Aneurysm with Alternative Methods in the Endovascular Stent Era. Mitsumasa Hata. Semin Thorac Cardiovasc Surg 2015; Summer; 27(2):106-112.

Editorial Commentary: It is Difficult to Compare Apples and Oranges: Acute and Chronic Type B Aortic Dissections, Complicated and Uncomplicated, are Different and Should be Treated as Such. Ourania Preventza. Semin Thorac Cardiovasc Surg 2015; Summer; 27(2):113-114.

News and Views: Treatment of Thoracic Aortic Aneurysm: Role of Earlier Intervention. Bulat A. Ziganshin. Semin Thorac Cardiovasc Surg 2015; Summer; 27(2);135-143.

Aortic root enlargement during aortic valve replacement: Nicks and Manouguian techniques. Kendra J Grub. Oper Tech Thorac Cardiovasc Surg 2015; Autumn; 20(3):206-218.

The Konno-Rastan procedure for anterior aortic annular enlargement. Mark E. Roeser. Oper Tech Thorac Cardiovasc Surg 2015: Autumn; 20(3):219-233. 